\title{
Aboriginal fisher perspectives on use of biotelemetry technology to study adult Pacific salmon
}

\author{
V.M. Nguyen ${ }^{(1) \star, ~ G . D . ~ R a b y ~}{ }^{(1)}$, S.G. Hinch ${ }^{(2)}$, S.J. Cooke ${ }^{(1)}$ \\ Received July 31, 2012 \\ Revised October 28, 2012 \\ Accepted October 29, 2012
}

\begin{abstract}
Key-words: telemetry

science, aboriginal fisher, radio-tracking, tagging, fisher attitude

Biotelemetry has become a popular tool accepted by the scientific community as a reliable approach for studying wild fish. However, stakeholder perspectives on scientific techniques and the information they generate are not uniformly positive. Aboriginal groups in particular may have opposition or apprehension to telemetry as a research tool. To that end, we conducted a river-bank survey of 111 aboriginal First Nations fishers that target adult Pacific salmon in the lower Fraser River, British Columbia, Canada. The majority of respondents had heard of telemetry, but few had knowledge of its function. Most responses regarding the use of telemetry in fisheries science were positive. The few negative perspectives were primarily concerned about the effects of tagging procedures whereas positive perspectives arose because telemetry was perceived to generate information on migration patterns and survival. Over half of the respondents would trust data arising from telemetry studies, but some had conditions related to the group conducting the research and their experience with fish handling. Several respondents noted the need for additional consultation and outreach with aboriginal communities (especially fishers) to better inform them of study questions and techniques which, in the case of telemetry studies, could promote better participation in tag return programs and uptake of knowledge emanating from use of telemetry.
\end{abstract}

\section{RÉSUMÉ}

Points de vue des pêcheurs autochtones sur l'utilisation des technologies de biotélémétrie pour l'étude du saumon du Pacifique adulte

Mots-clés:
télémétrie,
pêcheurs
autochtones,
radio-pistage,
marquage,
attitude
des pêcheurs

La biotélémétrie est devenue un outil courant accepté par la communauté scientifique comme une approche fiable pour l'étude des poissons sauvages. Toutefois, les perspectives des parties prenantes sur les techniques scientifiques et les informations qu'elles génèrent ne sont pas uniformément positives. Les groupes autochtones en particulier, peuvent avoir une opposition ou une appréhension à la télémétrie comme outil de recherche. À cette fin, nous avons mené une enquête sur le terrain auprès de 111 pêcheurs autochtones des "Premières nations " qui pêchent les adultes de saumon du Pacifique dans la partie inférieure du fleuve Fraser, en Colombie-Britannique, Canada. La majorité des répondants avaient

(1) Fish Ecology and Conservation Physiology Laboratory, Carleton University Department of Biology, Ottawa, ON, K1S 5B6, Canada

(2) Pacific Salmon Ecology and Conservation Laboratory, Centre of Applied Conservation Research and Department of Forest Sciences, University of British Columbia, Vancouver, BC, V6T 1Z4, Canada

* Corresponding author: vivian.m.m@gmail.com 
entendu parler de la télémétrie, mais peu avaient connaissance de sa fonction. La plupart des réponses concernant l'utilisation de la télémétrie dans les sciences halieutiques étaient positives. Les quelques réponses négatives étaient rares principalement préoccupées par les effets des procédures de marquage alors que des points de vue positifs ressortaient parce que la télémétrie a été perçue comme source d'informations sur les schémas de migration et de survie. Plus de la moitié des personnes interrogées feraient confiance à des données provenant d'études de télémétrie, mais certaines avaient des conditions liées à l'équipe en charge de la recherche et son expérience dans la manipulation du poisson. Plusieurs répondants ont souligné la nécessité de consultations supplémentaires et de sensibilisation auprès des communautés autochtones (en particulier les pêcheurs) afin de mieux les informer des questions de l'étude et des techniques qui, dans le cas des études de télémétrie, pourraient favoriser une meilleure participation aux programmes de retour de marques et montrer l'intérêt des connaissances émanant de l'utilisation de la télémétrie.

The fisheries science community continues to benefit from an ever-expanding suite of innovative tools and technology that enable the study of fish in their natural environment. Most notable is electronic tagging technology which has generated basic information on fish biology as well as informed the management and conservation of fish (reviewed in Lucas and Baras, 2000; Cooke et al., 2004; Cooke, 2008). There are a variety of electronic tagging tools but the most common type is biotelemetry where a signal emanating from a device carried by the animal (transmitter) sends the information to a receiver (Cooke et al., In Press). There are two primary types of signal propagation, using electromagnetic radiation (i.e., radio telemetry) and sound (i.e., acoustic telemetry). To conduct telemetry studies, irrespective of the technology, one must capture the fish, attach the device to the fish, and then release the animal and track it for some period of time. There are several different ways to attach devices to fish including gastric insertion, external attachment, and intra-coelomic surgical implantation, all of which have been well studied with respect to the effects of the transmitter and associated attachment procedures on the condition, health and survival of fish (see Bridger and Booth, 2000; Cooke et al., 2011). Indeed, a tenet of tagging is that tagged individuals exhibit the same behaviours and survival levels as untagged conspecifics (Brown et al., 2011).

Along with technical innovations, challenges can arise with how users of scientific knowledge and resource stakeholders view the technology and associated data it generates. Although the merits of biotelemetry as an advanced research technology are espoused by the scientific community (Winter, 1983; Lucas and Baras, 2000; Cooke et al., 2004; Cooke, 2008; Donaldson et al., 2008), stakeholders may not all feel the same way. There can be a variety of valid concerns regarding the effects of tags and tagging procedures on the animals, and thus concerns about the reliability of associated data or any management decisions based upon them. Our team has encountered this perspective while conducting research on the migration biology of Pacific salmon in the Fraser River, British Columbia (BC), Canada (summarized in Cooke et al., 2008; Cooke et al., 2012; Hinch et al., 2012). For example, in one study that involved working with the recreational fishing community, post-release mortality estimates were generated using two techniques - holding fish in net pens for $24 \mathrm{~h}$ and releasing them with radio transmitters and tracking them in the river (Donaldson et al., 2011). While conducting the study and during interaction with anglers before and after at various consultation meetings, we encountered significant opposition to use of telemetry based on the fact that anglers felt that the mortality estimates that they would generate would be inflated as a result of the tagging procedures. Even the management community has expressed concern about telemetry limitations (POST Fisheries and Oceans Canada report, 2012).

Along the Canadian south-Pacific coast, three fishing sectors compete for Pacific salmon: the commercial, recreational and aboriginal (in BC called First Nations) fishing sectors. The commercial sector (seine, troll, or gillnet gears) is a competitive fishery operating under individual 
quotas, of which several commercial First Nations economic opportunity fisheries operate in coastal and inland areas. The recreational sector operate on seasonal openings/closures to fishing, and the aboriginal sector have a communally-held right to fish for food, social, and ceremonial purposes (whereby the catch must be consumed, shared, or traded, but not sold), and are given priority under various treaties. Other stakeholders also include fish processors, export marketers, and non-governmental groups (DFO, 2011).

The aboriginal communities are important stakeholders (Dumont, 1993), and obtaining their permission is typically required to conduct research on their territories. Aboriginal representatives also frequently sit on various management bodies and the aboriginal community is the focus of extensive consultation by natural resource management agencies (McDaniels et al., 1994). We have encountered some apprehension from aboriginals while attempting to promote telemetry studies or present data based upon them. Given the importance of aboriginal perspectives, especially given their cultural and spiritual connections to fish (Lichatowich, 1999), it is impossible and irresponsible to ignore or dismiss their concerns. Knowledge of stakeholder perspectives on telemetry techniques and their application would help to identify the extent and basis of their concerns, thus providing opportunities to potentially address those issues proactively so that telemetry studies could be more fully embraced by stakeholders (Byers, 1999). To that end, we conducted semi-structured face-to-face interviews of the aboriginal First Nation fishing community in the lower Fraser River to understand their perspectives on the use of telemetry for studying adult Pacific salmon. To our knowledge this would be the first such study to explore stakeholder perspectives on biotelemetry. With expanding use of telemetry and other electronic tagging tools around the globe, we anticipate more potential conflict especially in aboriginal communities (e.g., the Arctic, Amazon Basin, central Africa). If not addressed, stakeholder apprehension could limit the potential of this technology to support evidence-based conservation and management initiatives.

We conducted face-to-face interviews with First Nation fishers and other members involved with the First Nation economic fishing process, including the First Nations' crew monitors, First Nation fish buyers, and buying employees. We included the latter groups ( $<10 \%$ of sample, herein referred to as fishing members) because they are highly involved with the fishing process and could equally possess valuable insight and perspectives on Pacific salmon science and management issues. The interviews followed a semi-structured approach, which allowed First Nation fishers and fishing members to identify additional topics regarding biotelemetry during the interview. The interviews consisted of a long and a short questionnaire. The short questionnaire was a subset of the long questionnaire. It included the same closed-ended questions only, and was intended to be for individuals that could only provide 5-10 min for the interview. The closed-ended questions asked respondents about sociodemographic questions (i.e., age, occupation, education, native band), as well as respondents' awareness of biotelemetry technology, awareness of current biotelemetry research in the Fraser River, and their understanding of biotelemetry science. The open-ended questions asked respondents about their thoughts regarding the use of biotelemetry to conduct research on salmon, and their trust in the results generated from biotelemetry. Interviewers provided a brief explanation on the function and purpose of radio-tracking, and showed a sample radio-tag prior to asking respondents their thoughts and trust in these techniques. The interview contained other questions not related to biotelemetry research (data not presented here). For the purpose of this paper, we focus on the questions relevant to understanding fishers' awareness and perspectives on the use of biotelemetry in Pacific salmon research.

Contact with the First Nation group representatives and leaders were made several months prior to the data collection to advertise the study and obtain permission to conduct the research. Interviews were conducted during two First Nations' economic opportunity (i.e., commercial) fisheries in 2011: (i) the sockeye gillnet fishery, and (ii) the pink salmon beach seine fishery. We did not conduct interviews during the food, social, ceremonial due to the privacy of these events and it is thus worth noting that we did not access the community elders who may be less receptive to technology. We had two interviewers at all times, but interviews were conducted one-on-one. The lead interviewer conducted the long questionnaire while 
the secondary interviewer conducted the short questionnaire. Crew leaders were identified and approached during rest times (i.e., in between net sets and during sorting). Effort was made to ensure all crew leaders participated in the long questionnaire. The crew leader was asked to be interviewed and subsequently asked for permission for interviewers to speak to the crew members. There was a mix of short and long questionnaires conducted among crew members. We aimed to interview all crew leaders and half of the crew members (or at minimum 2). Test interviews were conducted during the first sampling day, where we asked the first few participants for feedback specific to the interview structure and questions to improve subsequent interviews. Each interview had a preface with a statement explaining the purpose and source of the study to assure the participants that the interview data were confidential and anonymous. We obtained consent for audio recording and allowed for questions before beginning.

Closed-ended responses were tallied and presented as percent of responses out of the number of respondents who answered the relevant question. Responses about fishing members' thoughts on the use of telemetry to conduct Pacific salmon research were coded in to four themes: (i) negative, thoughts that were negative or against telemetry research; (ii) neutral, responses that were neither negative or positive, or both; (iii) positive conditional, responses that were positive but also with skepticism, hesitation or with a condition (e.g., if handling was not too stressful on fish); (iv) fully positive, responses that were positive with no hesitation. Furthermore, explanations for thoughts were thematized, and we use quotes throughout the paper to illustrate fishers 'perspectives about telemetry science. Responses about whether fishers' would trust results and conclusions generated from telemetry science were grouped into four categories: (i) No with legitimate reasons (i.e., reasons that are relevant to the question asked); (ii) neutral; (iii) yes but with condition, where respondents responded yes to trusting telemetry research but with a condition (e.g., research conducted but appropriate people), and; (iv) yes fully, where respondents were fully supportive and trusted telemetry results.

The sockeye gillnet fishery consisted only of the Chehalis First Nation Band and interviews were conducted between 24-26 August, 2011 during the $72 \mathrm{~h}$ fishery open time that occurred on 23 August 2010 at 18:00 and closed on 26 August, 2011 at 18:00. The sockeye fishery involved 46 crews (typically consisting of 2 fishers per crew). Interviews during the pink beach seine fishery involved several lower Fraser Valley First Nation bands, and occurred on the 14th, 17th-19th, and 24th of September, 2011, with an average of 32 crews participating over the opening fishing hours (total number of crews fishing ranged from 9 to 40 each fishing day). Each crew consisted of about six to twelve members and one crew leader. A large number of Chehalis First Nation fishers from the sockeye gillnet fishery were also participants in the pink beach seine fishery.

In total, we interviewed 111 First Nation fishing members, where $84 \%$ of respondents were male. The largest age group was $20-29$ years (29\%), followed by $24 \%$ between $30-39$ years, 18\% (40-59 years), 14\% (50-59 years), 10\% (under 20 years) ,and 6\% (60-69 years). The Chehalis First Nation Band was the most well represented group in our surveys (38\%), followed by members from the Sumas Band (10\%). The Peters Band, Seabird Band, Soowahlie Band, and others each represented $<10 \%$ of total survey respondents.

Of the 111 respondents interviewed, only 73 provided useful data about telemetry. Twenty two of 73 respondents interviewed $(30 \%)$ had not heard of radio telemetry, whereas 51 respondents $(70 \%)$ had (note: most of the telemetry studies in the Fraser over the past 15 years have involved radio rather than acoustic telemetry and also involved other fish species). When asked if respondents were aware of the ongoing telemetry studies occurring in the local rivers (Fraser and Harrison Rivers), 36 of 73 respondents (49\%) were not aware, 6\% were somewhat aware, and $45 \%$ were aware of the telemetry research program. A total of 36 out of 53 respondents $(68 \%)$ had no knowledge or understanding of the function of radio-tags and tracking, while only $28 \%$ had prior knowledge of radio-tracking, and $4 \%$ had some knowledge.

Sixty eight interviewed fishers provided useable responses regarding their thoughts on radiotracking and telemetry research. Only two of the 68 responses (3\%) were negative, $22 \%$ were neutral, $16 \%$ were positive conditional, and $59 \%$ were fully positive. The two respondents 
that provided negative thoughts were primarily concerned about the stressful technique of gastric tagging (see Cooke et al., 2005 for more details on the tagging procedure) and the potential of disturbing their migration patterns with handling procedures and tags. Many of the respondents who provided a neutral answer said they "don't mind it", "it's good, I guess", "so-so", or "it's fine". Additionally, neutral answers were responses that were both negative and positive where some respondents said it was "a good idea, but not so good because you have to handle it first and insert the tag", or they thought it was informative but still stressful for the fish. Of the responses that were positive but with conditions, the condition in $70 \%$ of cases was that it did not harm or stress the fish, and so "It's a good thing as long as it's not hurting fish". Lastly, of the fully positive responses, $65 \%$ of participants thought it was a "good idea", "liked it", they were "impressed" or thought it was "cool". Fifteen respondents had positive thoughts about telemetry because of the biological knowledge it could generate (e.g., migration patterns, location of fish, migration success rates). We were somewhat surprised of this finding given the strong emphasis on traditional ecological knowledge and wisdom within First Nations communities in British Columbia (Turner et al., 2000) which might lead to perspectives that such technology is unnecessary.

Only $7 \%$ of 68 respondents indicated that they would not or would not fully trust results from telemetry research. Reasons included the uncertainty of "what tags can do to the fish", "the fish's natural instincts are messed up", "some of them could get caught and not make it to spawning grounds" (i.e., unreported recaptures of tagged fish), and "there could be technical difficulties or water damage to the tags." Another, $10 \%$ of respondents gave neutral responses, which were respondents that were indifferent about the topic, would "probably" trust the results, or thought "why not". Furthermore, $17 \%$ of respondents were supportive of telemetry conclusions but with certain conditions. These conditions are similar to their general thoughts of tagging and included whether research was "done properly", conducted by a trusted source, or simply general skepticism. One respondent said, "Depends on who does [the research]. You need the history and the people who lived it. How can I believe you if I can't believe myself? I would not trust the government or universities." This respondent, however, identified that they would trust someone that had lived and worked with the people and with salmon for years.

Over half of the interviewed fishing members (65\%) would fully trust the telemetry results, where most of the reasoning is reflected in their thoughts of telemetry science. One respondent said, "You have to put trust into it. It needs to be done to understand the dynamics, and it will give everybody understanding all the way around." We should note that three respondents emphasized the need for raising awareness among the First Nation fishing community about the radio-tags and telemetry programs in order to improve reporting of transmitter recaptures by fishers and help ensure the programme is successful. One respondent said, "Would be good to see more [tagging] in order for people to believe they are actually out there. In 10 years, l've only seen 2 tags. There is a need for more education about what the tag study is for. There needs to be education that it's not about population control. Natives are skeptical about information from tags, snout and scale samples. [The fishers] are scared that [the Department of Fisheries and Oceans (DFO)] will take them out of the water. We need to show that it's not negative science." Another respondent said it was unfair between the First Nation fishers and recreational fishers - "I just got a ball cap [when I returned tags], while the sporties [recreational anglers] get entered into a draw for new motor boats. People [researchers] won't pick [the tags] up and I caught about 30 tags. I ended up not doing anything with the tags." Another respondent said that, "I usually get monitors to take the tags in. People were not returning the tags. Only if someone can take them off their hands, but DFO did not want to work with fish monitors to get the tags."

Clearly there is a need to better communicate the goals of telemetry studies to stakeholders as well as share information on the capabilities and limitations of biotelemetry. Such efforts could promote better participation in tag return programs (Cardona-Pons et al., 2010) as well as lead to stakeholders embracing findings emanating from the use of biotelemetry. Conservation initiatives arising from biotelemetry-based research could require buy-in from First 
Nations groups to succeed, especially if changes to fishing practices are involved. Of interest in this study was the fact that the stakeholders had such concern for the welfare of tagged fish (Diggles et al., 2011), which emphasizes the need to ensure that tagging techniques are validated and done in a manner that maintains the welfare status of tagged fish. This perspective is in line with that of the research team because maximizing fish welfare is conducive to minimizing handling/tagging effects, an inherent objective of any tagging study (Brown et al., 2011). We had anticipated there might be concerns voiced that tagging equated with "playing with food", a perspective that aboriginals often have towards catch-and-releasing angling (Haggen et al., 2007). That was clearly not the case here, likely because those surveyed could easily discern the difference between research and recreational angling. However, it may also reflect the fact that we did not survey community elders or target fishers that were participating in the traditional ceremonial fisheries (fishing for social gatherings such as weddings, funerals, etc.). In fact, we found a surprisingly high proportion of respondents who take part in recreational angling in addition to aboriginal fishing ( $80 \%$; part of a separate survey, Nguyen, unpublished data). In other words, the fact that these (mostly young) aboriginal fishers were participating in non-traditional "economic opportunity" fisheries (essentially small scale commercial fisheries) and selling their catch may have influenced their perspectives.

Although we focused on aboriginal First Nations fishers in the lower Fraser River, we believe that these general messages apply elsewhere, especially in areas with aboriginal peoples or other stakeholders with close connections to natural resources. Case studies from around the world have shown that research-oriented and conservation programs are likely to be more successful if key stakeholders and networks are incorporated (e.g., Arlinghaus et al., 2007; Granek et al., 2008). Fishers (from various fishing sectors and fisheries) may offer significant resources, such as knowledge of spatial patterns of resource use and availability, direct involvement in research and restoration projects, political leverage, and grassroots support for research and conservation measures. Such partnerships among managers, scientists and stakeholders are effective at increasing local capacity and fundraising, generating data, and providing education and incentives for local people to protect natural resources (Granek et al., 2008; Li et al., 2010). We suggest that when undertaking telemetry studies, or frankly any studies that use novel techniques for animal research, that efforts be made to engage stakeholders early in the process (Byers, 1999). Doing so will enable the scientists to understand stakeholder perspectives and to work collaboratively with them on overcoming apprehension to using technology based on open and transparent dialogue. This may be most salient for studies where potentially invasive procedures are used on live animals, especially species that are of direct value (economic, cultural, spiritual, consumptive) to the stakeholders. This is critical for a number of reasons, not the least of which is that aboriginal communities can exclude or otherwise regulate outsiders (i.e., researchers; Martin, 2008), which could make it impossible to collect data. Building understanding and trust between resource users and scientists is crucial to ensuring that relevant research is carried out and that the resulting knowledge can be used stakeholders.

\section{ACKNOWLEDGEMENTS}

We are grateful to members of the First Nations fishing communities of the lower Fraser River for their helpful and generous participation in this and other studies in recent years. We thank Natalie Sopinka and Nolan Bett with assistance in conducting interviews in the field. Matthew Parslow and Karen Burnett from Fisheries and Oceans Canada provided logistic support. This work was supported by the National Sciences and Engineering Research Council of Canada (NSERC, in the form of a Strategic Grant to SJC and SGH). VMN was supported by an Ontario Graduate Scholarship and GDR was supported by an NSERC postgraduate scholarship. SJC is supported by the Canada research Chairs program and NSERC OTN Canada. 


\section{REFERENCES}

Arlinghaus R., Cooke S.J., Lyman J., Policansky D., Schwab A., Suski C., Sutton S.G. and Thorstad E.B., 2007. Understanding the complexity of catch-and-release in recreational fishing: an integrative synthesis of global knowledge from historical, ethical, social, and biological perspectives. Rev. Fish. Sci., 15, 75-167.

Bridger C.J. and Booth R.K., 2003. The effects of biotelemetry transmitter presence and attachment procedures on fish physiology and behavior. Res. Fish. Sci., 11, $13-34$.

Brown R.S., Eppard M.B., Murchie K.J., Nielsen J.L. and Cooke S.J., 2011. An introduction to the practical and ethical perspectives on the need to advance and standardize the intracoelomic surgical implantation of electronic tags in fish. Rev. Fish Biol. Fish., 21, 1-9.

Byers T., 1999. Perspectives of aboriginal peoples on wildlife research. Wildlife Soc. B, 27, 671-675.

Cardona-Pons F., Morales-Nin B. and Sutton S.G., 2010. Scientists and recreational fishers: Communication manners and its efficiency. Fish. Sci., 106, 575-578.

Cooke S.J., 2008. Biotelemetry and biologging in endangered species research and animal conservation: relevance to regional, national, and IUCN Red List threat assessments. Endangered Species Research 4, 165-185.

Cooke S.J. and Thorstad E.B., 2012. Is radio telemetry getting washed downstream? The changing role of radio telemetry in studies of freshwater ichthyofauna relative to other tagging and telemetry technology. Am. Fish. Soc. Symp., 76, 349-369.

Cooke S.J., Hinch S.G., Wikelski M., Andrews R.D., Wolcott T.G. and Butler P.J., 2004. Biotelemetry: a mechanistic approach to ecology. Trends Ecol. Evol. (Invited Review), 19, 334-343.

Cooke S.J., Crossin G.T., Patterson D.A., English K.K., Hinch S.G., Young J.L., Alexander R., Healey M.C.,Van Der Kraak G. and Farrell A.P., 2005. Coupling non-invasive physiological and energetic assessments with telemetry to understand inter-individual variation in behaviour and survivorship of sockeye salmon: development and validation of a technique. J. Fish Biol., 67, 1342-1358.

Cooke S.J., Hinch S.G., Farrell A.P., Patterson D.A., Miller-Saunders K., Welch D.W., Donaldson M.R., Hanson K.C., Crossin G.T., Olsson I., Cooperman M.S., Mathes M.T., Hruska K.A., Wagner G.N., Homason R., Hourston R., English K.K., Larsson S., Shrimpton J.M. and Van Der Kraak G., 2008. Developing a mechanistic understanding of fish migrations by linking telemetry with physiology, behaviour, genomics and experimental biology: an interdisciplinary case study on adult Fraser River sockeye salmon. Fisheries, 33, 321-338.

Cooke S.J., Woodley C., Eppard M.B., Brown R.S. and Nielsen J.L., 2011. Advancing the surgical implantation of electronic tags in fish: a gap analysis and research agenda based on a review of trends in intracoelomic tagging effects studies. Rev. Fish Biol. Fish., 21, 127-151.

Cooke S.J., Hinch S.G., Donaldson M.R., Clark T.D., Eliason E.J., Crossin G.T., Raby G.D., Jeffries K.M., Lapointe M., Miller K., Patterson D.A. and Farrell A.P., 2012. Conservation physiology in practice: How physiological knowledge has improved our ability to sustainably manage Pacific salmon during up-river migration. Phil. Trans. R. Soc. B, 367, 1757-1769.

Cooke S.J., Hinch S.G., Lucas M.C. and Lutcavage M., In Press. Chapter 18 - Biotelemetry and biologging. In: Zale A.V., Parrish D.L. and Sutton T.M. (eds.), Fisheries Techniques, 3rd edition. American Fisheries Society, Bethesda, Md.

Department of Fisheries and Oceans Canada (DFO), 2011. Aboriginal fishing and treaties in the Pacific region. http://www.pac.dfo-mpo.gc.ca/abor-autoc/index-eng.htm. Date accessed: 20 October, 2012.

Diggles B.K., Cooke S.J., Rose J.D. and Sawynok W., 2011. Ecology and welfare of aquatic animals in wild capture fisheries. Rev. Fish Biol. Fish., 21, 739-765.

Donaldson M.R., Hinch S.G., Patterson D.A., Hills J., Thomas J.O., Cooke S.J., Raby G.D., Thompson L.A., Robichaud D., English K.K. and Farrell A.P., 2011. The consequences of angling and beach seine capture on the physiology, post-release behaviour and survival of adult sockeye salmon during upriver migration. Fish. Res., 108, 133-141.

Dumont J., 1993. Aboriginal perspectives of the natural environment. Theytus Books Ltd., Penticton.

Granek E.F., Madin E.M.P., Brown M.A., Figueira W., Cameron D.S., Hogan Z. Kristinason G., De Villers P., Williams J.E., Post J., Zahn S. and Arlinghaus R., 2008. Engaging recreational fishers in management and conservation: global case studies. Cons. Biol., 22, 1125-1134. 
Haggan N., Ainsworth C., Pitcher T.J. and Heymans J.J., 2007. Life in the fast food chain: où sont les poisons d'antan? In: Parrish C.C., Turner N. and Solberg S. (eds.), Resetting the kitchen table: Food security, culture, health and resilience in coastal communities, Nova Science Publishers, New York, 51-74.

Hinch S.G., Cooke S.J., Farrell A.P., Miller K.M., Lapointe M. and Patterson D.A., 2012. Dead fish swimming: early migration and premature mortality in adult Fraser River sockeye salmon. J. Fish Biol., 81, 576-599.

Li O., Sutton S.G. and Tynan L., 2010. Communicating scientific information to recreational fishers. Hum. Dimens. Wildl., 15, 106-118.

Lichatowich J., 1999. Salmon Without Rivers. Washington, DC: Island.

Lucas M.C. and Baras E., 2000. Methods for studying the spatial behaviour of freshwater fishes in their natural environment. Fish Fish., 1, 283-316.

Martin K., 2008. Please knock before you enter: Aboriginal regulation of outsiders and the implications for researchers. Teneriffe, QLD: Post Pressed.

McDaniels T., Healey M. and Paisley R., 1994. Co-operative fisheries management involving first nations in British Columbia: An adaptive approach to strategy design. Can. J. Fish. Aquat. Sci., 51, 2115-2125.

Turner N. J., Ignace, M. B. and Ignace R., 2000. Traditional Ecological Knowledge and Wisdom of Aboriginal Peoples in British Columbia. Ecol. Appl., 10, 1275-1287.

Winter J.D., 1983. Underwater biotelemetry. In: Nielsen L.A. and Johnson D.L. (eds.), Fisheries techniques. American Fisheries Society, Bethesda, Maryland, 371-395. 